\title{
Análise em um Sistema de Informação Geográfica (SIG) das alterações na paisagem em ambientes adjacentes a plantios de pinus no Distrito do Estreito, município de São José do Norte, Brasil *
}

\author{
GIS analysis of landscape changes in environments adjacent to pinus forests in \\ district of Estreito, São José do Norte, Brazil
}

\author{
Kahuam S. Gianuca ${ }^{\circledR, 1}$, Carlos Roney A. Tagliani $^{1}$
}

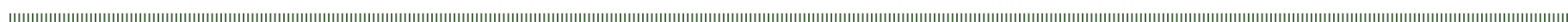

\section{RESUMO}

Localizado em uma extensa restinga litorânea na regiāo costeira do Rio Grande do Sul, o município de São José do Norte caracteriza-se por apresentar uma das menores densidades demográficas do Estado e uma economia baseada na silvicultura, agricultura e na pesca. A retração do setor agrícola e pesqueiro a partir da década de 70 e a desvalorização das propriedades rurais resultaram em condiçóes propícias para a expansão do setor florestal, representado principalmente pela exploração de pinus. Na regiáo do Distrito do Estreito a maioria dos plantios em grande escala foi estabelecida sobre planícies arenosas próximas à praia. Foram analisados em um Sistema de Informaçóes Geográficas dois cenários (1964 e 2007) e, a partir da elaboração de mapas temáticos e análise ambiental, constatou-se que os florestamentos de pinus quando implantados próximos à praia, podem ser responsáveis por alteraçôes na dinâmica de ambientes costeiros como dunas, brejos úmidos, banhados, lagoas e campos. Na área de estudo, as plantaçôes de pinus ocupam 1.581 hectares, estabelecidas sobre dunas transgressivas e brejos úmidos. Esses plantios próximos ao sistema de dunas podem ter interferido no processo de migraçáo de dunas transgressivas em direçáo as lagoas e banhados, e também, barrado o transporte eólico lateral que alimentava planícies arenosas localizadas ao Sul da área de estudo, onde atualmente ocorrem brejos úmidos. $\mathrm{O}$ efeito de barreira causado pelos plantios pode ter resultado no represamento das águas do sistema de lagoas do Estreito, diminuindo o número de sangradouros. Essas alteraçôes interferem nos processos naturais e podem causar a homogeneização da paisagem, fragmentação de habitat e perda de biodiversidade. Os resultados desse estudo podem contribuir para a gestão dos recursos naturais nas zonas costeiras. A identificaçâo das alteraçôes na paisagem caudas por intervençôes antrópicas e a análise da dinâmica dos ambientes alterados pode servir de subsídio para o pranejamento das atividades e o manejo sustentável da áreas naturais.

Palavras-chave: SIG, pinus, uso do solo, manejo.

@ - Autor correspondente: kgianuca@gmail.com

1 - Universidade Federal do Rio Grande (FURG), Instituto de Oceanografia (IO) Cx. Postal, 474 96201-900, Rio Grande, RS, Brasil. e-mails: kgianuca@gmail.com; ctagliani@log.furg.br 


\section{ABSTRACT}

Located in a long and narrow sandy spit in the coastal zone of Rio Grande do Sul state, the city of São Jose do Norte is characterized as having one of the lowest demographic density rates in the state, with the economy being based on silviculture, agriculture, and fishing. The decline of agricultural and fishing sectors in the 70's and the devaluing of rural properties have resulted in perfect conditions for the expansion of the forestry sector, mainly represented by pinus harvesting. Such activity plays an important role in the city's socioeconomy, employing over half of the labor force and contributing with 73\% of its GDP.

The Estreito region is quite diverse in ecological and environmental aspects. It presents a rich mosaic of environments formed by an important system of coastal lagoons, marshes, native forests, fields, humid slacks, dunes, beaches, and extensive pine forest.

Most large-scale pine plantations have been established on sandy plains near the beach, and may be responsible for changes in environmental dynamics.

The population increase, the settlement of significant urban centers, industries, portuary complex, the development of agriculture and fishing are historic features observed along the coastal areas worldwide. In recent decades, the pressure of use of coastal resources has increased significantly, which increased the conflicts of land use. This situation has led governments to invest more in programs for integrated coastal management (GCI) as a way to sustainably management.

The landscape changes resulting from the interference of pine forests in the natural environment on study area, were analyzed in a GIS. The database for this study consisted of aerial photographs at scale 1:60.000 held in 1964, and a digital satellite image Landsat 5 TM, orbit point221_082, spatial resolution of $30 \mathrm{~m}, 26 / 05 / 2007$.

Aerial photographs were scanned with 600 dpi resolution, grayscale 8 bit color and stored in bitmap (bmp). After processing and editing of aerial photographs and Landsat image, we constructed a mosaic of aerial photographs that represented the area of interest. All images were georeferenced using Resample module of IDRISI ANDES GIS, which performs a systematic transformation that gently "adjust" the image based on the known locations of a set of ground control points or using a georeferenced image base. Georeferencing was based on the SAD 69 datum, UTM projection system, observing the Cartographic Accuracy Standard (PEC).

With two georeferenced images of study area (1964 mosaic and 2007 LANDSAT image), a both were cut in the same proportions to make them exactly the same number of rows and columns and same spatial resolution. With the photo-interpretation and recognition of classes of landscape in field trips, the images was classified with the Cartalinx software. Were defined land use classes mapped in both situations (1964 and 2007).

With the images properly scanned and georeferenced, conducted the analysis in the GIS IDRISI, where tools to reclassification and crossexamination, it was possible to analyze the time-space variation between different use classes mapped to the two situations analyzed (Map 1 - 1964 and Map 2 - 2007). The changes were quantified in acres and calculated data for GIS and digitally represented in tables.

Examining landscape changes in study area using a GIS, it was found that the plantations near the beach may interfere with environments dynamic and characterization of the area where they are deployed. distribution of coastal creeks, contention of mobile dunes, habitat fragmentation, and biodiversity loss.

The pinus forests occupy 1,581 hectares, mainly established over transgressive dunes and humid slacks. Approximately 1,500 hectares of Transgressive dunes and humid slacks were completely removed by these plantations, resulting in decreased of fauna and flora eradication. Those forests near the dune system may have interfered with the migration process of transgressive dunes towards lagoons and wetlands as well as blocked lateral aeolian transport which fed sandy plains located further South, where humid slacks currently are found.

The barrier formed by the forests may have dammed up the waters in the Estreito lagoon system, thus reducing the number of coastal creeks.

The same hipotesys made for increasing the level of the lagoons may be related to the marshes, wich are associated with the lagoon system and showed a significant increase in their area.

Significant changes were observed in other environments, probably resulting from the interference of pine forest in the natural processes of coastal dynamics, such as transport wind, water flow and ecological succession.

The results achieved have great relevance to coastal management and aims to contribute to the management of the activities according to its aptitude and restriction areas, thus fostering a more effective and sustainable management.

Keywords: GIS, pine, land use, management.

\section{INTRODUÇÁO}

A elevada concentração populacional, o assentamento de expressivos centros urbanos, industriais, portuários, turísticos e o desenvolvimento de atividades agrícolas e pesqueiras são características históricas observadas ao longo das zonas costeiras no mundo todo. Nas últimas décadas, a pressão de uso dos recursos costeiros tem aumentado significativamente, o que intensificou, na mesma medida, os conflitos gerados. Essa situação, tem levado os governos a investir cada vez mais em programas de gerenciamento costeiro integrado (GCI) como forma de gerenciar de forma sustentável tais conflitos.
O GCI consiste em um processo contínuo e dinâmico pelo qual são elaboradas decisões e ações para o uso sustentável, desenvolvimento e proteção das áreas costeiras e recursos marítimos (Tagliani, 2002).

No Brasil, o Plano Nacional de Gerenciamento Costeiro foi publicado através da Lei 7.661 de 1988, com apoio político e jurídico da Comissão Interministerial para os recursos do Mar - CIRM; e do Conselho Nacional do Meio Ambiente CONAMA.

Atualmente, com o objetivo de descentralizar e multiplicar as açóes, foi estabelecido o Programa Nacional de Gerenciamento Costeiro - GERCO, sob a coordenação do Ministério do 
Meio Ambiente - MMA. O GERCO articula com os governos dos 17 estados litorâneos através dos seus respectivos órgãos ambientais, no papel de executores estaduais, os quais buscam integrar suas açôes com os municípios.

A Planície Costeira do Rio Grande do Sul (PCRS) é uma ampla área sedimentar com $70 \mathrm{~km}$ de largura e $640 \mathrm{~km}$ de extensão e que abriga um imenso complexo estuarino-lagunar de grande importância socioeconômica e ambiental. A evolução geológico-geomorfológica dessa área remonta ao período Terciário, onde o transporte e deposição de sedimentos oriundos das áreas mais elevadas foram retrabalhados pela ação de processos físicos costeiros e pelas variaçóes do nível do mar durante o Pleistoceno e Holoceno (Villwock, 1984).

Como resultado desse processo evolutivo, surgiu na PCRS uma paisagem composta atualmente por um rico mosaico de ambientes: matas nativas, campos, banhados, lagoas, dunas, marismas e uma extensa praia arenosa. A interação de fatores como a alta disponibilidade de sedimentos arenosos, a marcante ação das ondas e correntes, a intensa açáo eólica e a ocupação e uso do solo - exploração dos recursos - resulta numa dinâmica que representa um valioso objeto de estudo, permitindo inúmeras abordagens.

A área de estudo localiza-se no município de São José do Norte, situado em uma extensa e estreita restinga litorânea entre o Oceano Atlântico e a Lagoa dos Patos. Atualmente, o município possui 24.905 habitantes, em uma área de 1.135,30 $\mathrm{km} 2$ e uma das menores taxas de densidade demográfica do estado, 22,3 hab/km2.

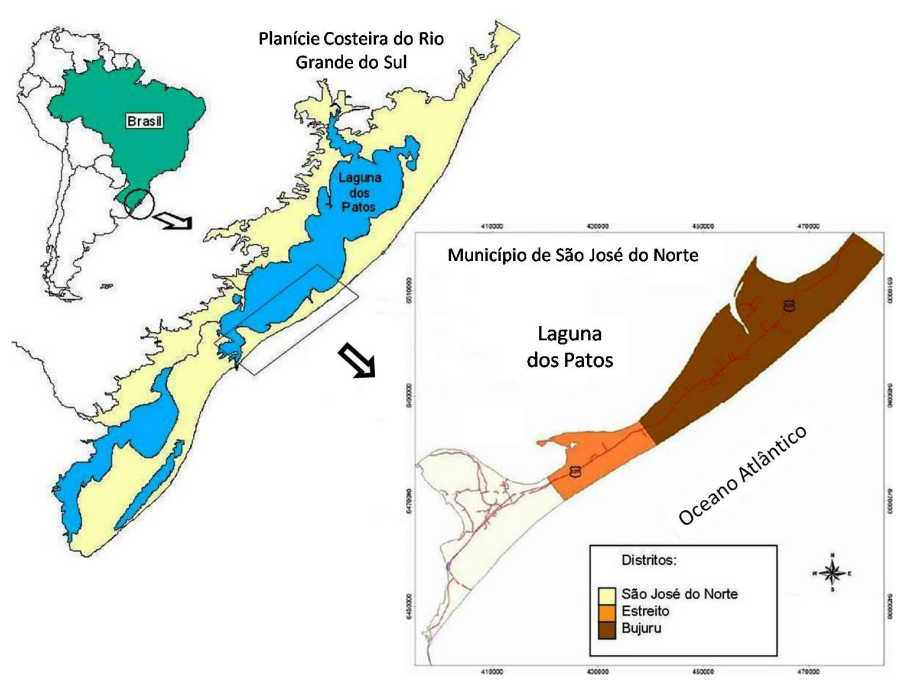

Figura 1. Localização do Município de São José do Norte. Figure 1. São José do Norte.

Sua economia é centrada em atividades do setor primário tais como: agricultura, pesca e silvicultura. (IBGE, 2007). Essas atividades e os serviços gerados, contribuiram com aproximadamente $84 \%$ do PIB [Produto Interno Bruto: soma em valores monetários de todos os bens e serviços finais produzidos numa determinada regiáo (paises, estados, cidades), durante um periodo determinado (mês, trimestre, ano)] municipal em 2005, já em 2007, a participação do setor florestal foi de $73 \%$ do PIB municipal (Grando \& Adelar, 2008).
O setor florestal em São José do Norte é uma atividade relativamente recente (iniciou na década de 70), mas que tem aumentado muito e se tornado a principal fonte de renda do município. O setor é representado principalmente pela exploração de pinus que ocupa uma área de aproximadamente 13.000 hectares, contribui com $73 \%$ do PIB e emprega mais de metade da mão-de-obra do município (Gianuca, 2009).

Devido a uma grande capacidade de adaptação, o gênero pinus é considerado como um dos principais invasores exóticos do globo e os impactos ambientais de seu cultivo vêm sendo discutidos em escala mundial (Bechara, 2003).

O geoprocessamento é uma importante ferramenta técnica para a análise de fenômenos com expressão territorial, permitindo espacialização do território através da quantificação, qualificação e localização, bem como o relacionamento com outras variáveis espaciais.

As alteraçôes causadas nas paisagens e sua representação espacial, hoje são possíveis com o uso de Sistemas de Informação de Geográfica (SIG) que são um conjunto de tecnologias voltadas à captação, armazenamento, manipulação e edição de dados georreferenciados. Análises espaciais baseadas no uso do geoprocessamento possuem uma vasta gama de aplicaçóes, gerando subsídios para açôes de manejo e planejamento ambiental e para diagnosticar alteraçóes na paisagem e conflitos de uso do solo.

Machado et al. (2003), simulou cenários alternativos de uso do solo em uma microbacia em Piracicaba (SP), utilizando técnicas de modelagem e geoprocessamento, os resultados permitiram identificar áreas sensíveis ambientalmente e sujeitas a diferentes níveis de manejo.

Ferramentas de geoprocessamento como os SIG's tem sido intensamente utilizadas na elaboraçáo dos Planos Ambientais Municipais. Esses Planos consistem num instrumento de gestáo voltado ao controle e monitoramento das atividades efetiva ou potencialmente causadora de degradação ambiental, exigidos a cada município para que estes se responsabilizem pelo licenciamento de atividades de impacto local (Lei Estadual no 10.330 de 27 de dezembro de 1994 e Resolução do CONSEMA no 011 de 17 de novembro de 2000). Nesse sentido, as técnicas de geoprocessamento aplicadas aos SIG's permitem a espacialização dos fenômenos e identificação dos conflitos de acordo com critérios pré-estabelecidos para a análise.

O objetivo desse trabalho é avaliar as alterações na paisagem em áreas adjacentes aos plantios de pinus próximos a Barra do Estreito em São José do Norte/RS, entre os anos 1964 e 2007, através de técnicas de geoprocessamento em um SIG.

\section{2. ÁREA DE ESTUDO}

A área selecionada para o estudo localiza-se entre os distritos de São José do Norte e Estreito, cobrindo uma área de 7.746 hectares, entre os paralelos $31^{\circ} 57^{\prime} 06^{\prime \prime}$ e $31^{\circ}$ 49' 09” latitude Sul e os meridianos $51^{\circ} 52^{\prime} 21^{\prime \prime}$ e $51^{\circ} 42^{\prime}$ $08^{\prime}$ "longitude Oeste; está limitada a sudeste pelo oceano Atlântico e a noroeste pela BR-101.

A regiáo do Estreito é bastante diversificada em aspectos ecológicos e ambientais. Apresenta um rico mosaico de ambientes formado por um importante sistema de lagoas litorâneas, banhados, matas nativas, campos, brejos úmidos, dunas e praias, além de extensos florestamentos de pinus. (Fig.3). 


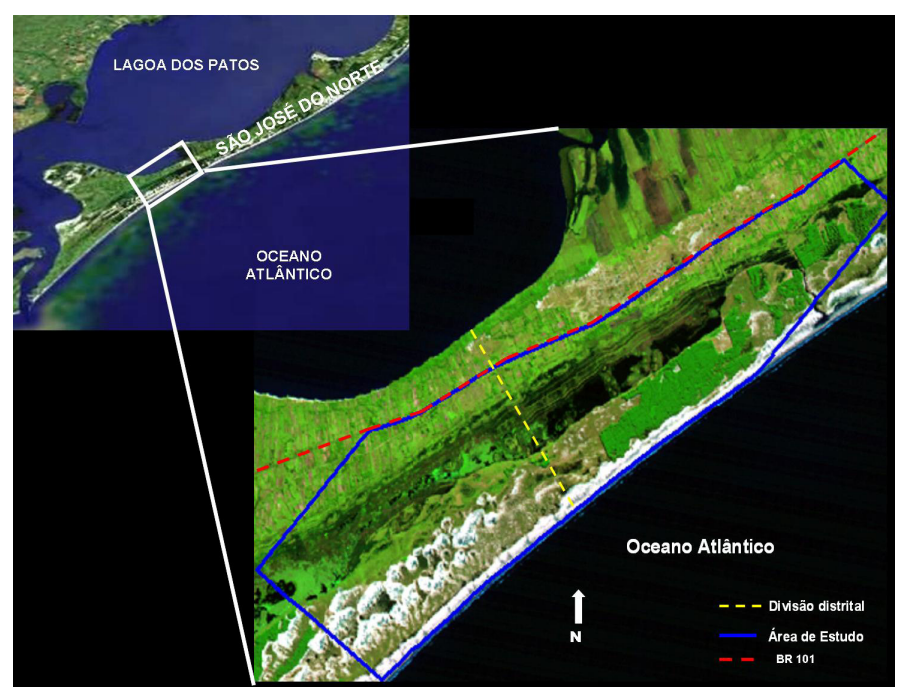

Figura 2. Localização da área de estudo.

Figure 2. Location of the Study area.

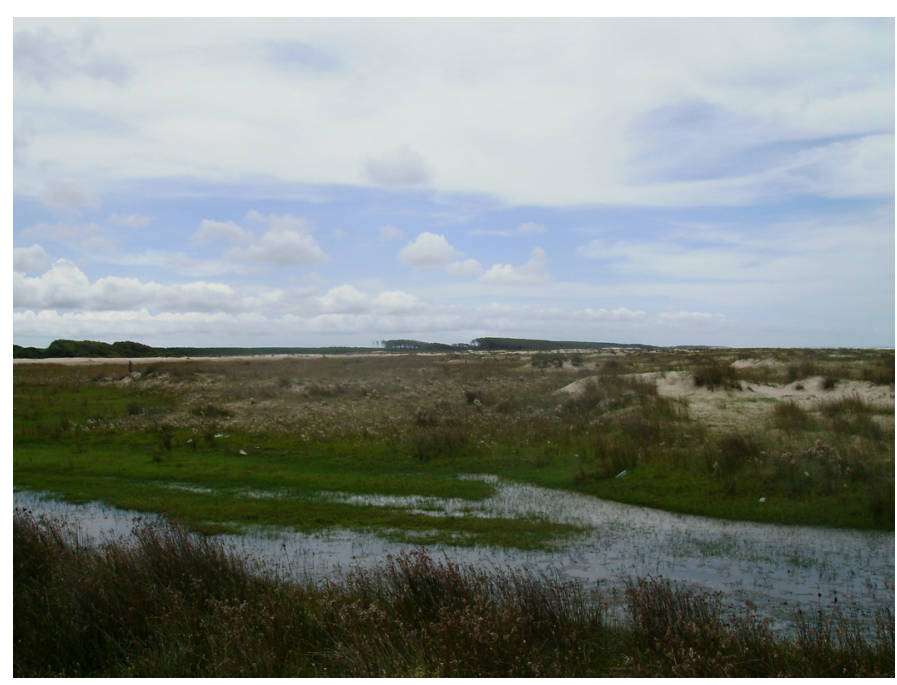

Figura 3. Diversidade de ambientes na área de estudo.

Figure 3. Enviromental diversity in study area.

A maior parte da área é formada por solos hidromórficos arenosos de baixa fertilidade (Neossolos Quartzarênicos), onde ocorrem campos de dunas, brejos e quase a totalidade dos florestamentos de pinus. As áreas baixas associadas às lagoas e banhados são formadas por Gleissolos pouco húmicos e nas áreas mais altas, Planossolos desenvolvidos de sedimentos argilosos de média fertilidade, propícios ao cultivo agrícola, representados pelos campos litorâneos a noroeste e norte.

Os campos na regiáo do Estreito são utilizados para agricultura representada principalmente pelas lavouras anuais de arroz - desenvolvidas nos terraços lagunares - e cebola, e pela pecuária.

Acompanhando uma falésia de abrasão marinha fóssil ocorrem as maiores extensôes de mata de restinga do município, sendo que nas outras áreas a vegetação é caracterizada principalmente por espécies de campos e banhados (Tagliani, 2002).
Nessa regiáo estáo localizados alguns dos maiores corpos lagunares do município. As lagoas Tuneira, São Caetano, Saraiva e Estreito, compóem um importante sistema de lagoas interligadas, formado há aproximadamente 4.500 anos a.p. pelo isolamento desses corpos pelo sistema Laguna/ Barreira IV, de formação Holocênica. (Gianuca, 2009).

Associadas ao sistema lagunar ocorrem as maiores extensóes de banhados do município, como o banhado Vitória. Esses recursos hídricos são utilizados principalmente para irrigaçáo das lavouras com o uso de bombeamento hidráulico.

O sistema de praia extende-se por aproximadamente $13,5 \mathrm{~km}$. Segundo Figueiredo \& Calliari (2005), na regiáo do Farol do Estreito ocorrem Neossolos Quartzarênicos de texturas médias e grossas que conferem a essa região características de praias intermediárias. A faixa de praia apresenta declive acentuado, escarpas erosionais e cúspides praiais desenvolvidos.

\section{MATERIAIS E MÉTODOS}

A metodologia utilizada na análise envolveu quatro etapas:

\section{Etapa 1 - Elaboraçáo e formatação do banco de dados}

A base de dados para este estudo incluiu fotografias aéreas de um levantamento aerofotogramétrico na escala de 1:60.000 realizado em 1964, e de uma imagem de satélite LANDSAT TM 5 em formato digital, órbita-ponto 221_082, resolução espacial de $30 \mathrm{~m}$, de 26/05/2007.

As fotografias aéreas foram digitalizadas com o uso de um scanner com a definição de $600 \mathrm{dpi}$, coloração em escalas de cinza de 8 bit, usando o professional mode e armazenadas em formato bitmap (bmp).

A maioria dos equipamentos utilizados na aquisição de fotografias aéreas apresenta lentes que captam o solo em uma projeção cônica, fazendo com que as bordas apresentem altos índices de distorção, e o centro, distorção desprezível. Utilizando-se apenas os centros das aerofotos, esse problema pode ser amenizado sem grandes limitaçóes.

Para diminuir as distorçôes, as imagens aéreas foram recortadas na proporção de $60 \%$ com o uso do software Adobe Photoshop, que também foi usado para o realce de contraste e nitidez. $\mathrm{O}$ realce de contraste e nitidez, realizado tanto nas imagens aéreas como na imagem LANDSAT TM 5, facilitou a fotointerpretação e a identificação de pontos de controle para o georreferenciamento.

Para a análise da totalidade da área de interesse foi necessária a elaboração de um mosaico com quatro imagens aéreas utilizando o software Regeemy. Esse software produzido pelo INPE e pela Universidade da Califórnia permite mosaicar de forma rápida e fácil imagens de satélite, fotografias aéreas, fotos de câmeras digitais e imagens de modo geral, permitindo também, o controle do erro durante o processo.

\section{Etapa 2 - Georeferenciamento}

O georreferenciamento das imagens foi realizado pelo módulo Resample do SIG IDRISI ANDES, que realiza uma transformação sistemática que suavemente "ajusta" a imagem com base nas posições conhecidas de um conjunto 
de pontos de controle em terra ou usando uma imagem georreferenciada como base.

Foi usada uma função de mapeamento Linear, a qual requer no mínimo quatro pontos de controle. Para o mosaico de fotografias aéreas foram utilizados oito pontos de controle de acordo com coordenadas UTM extraídas do software Google Earth Pro.

O Erro Médio Quadrado (RMS), descreve o erro de posicionamento característico de todos os pontos de controle em relação à equação de melhor ajuste. Ele representa a probabilidade com a qual uma posição mapeada poderá variar de sua localizaçáo verdadeira.

De acordo com os padróes de precisão dos mapas dos Estados Unidos (U.S. National Map Accuracy Standards, 1947), mapas com escala maior que 1: 20.000 devem apresentar menos de $10 \%$ dos pontos testados com erros maiores que $1 / 50$ polegadas (Eastman, 2006).

No Brasil, segundo o Padrão de Exatidáo Cartografica (PEC) a conversão dos padróes de precisão em análises estatísticas do RMS aceitável, requer que 90\% dos erros acidentais não sejam maiores que 1,6449 vezes o RMS (D.O.U., 1984).

Admitiu-se, portanto, para a escala de 1:60.000, um RMS menor que 0,01 , representando erro no terreno de menos de 15 metros, considerado aceitável de acordo com os padróes do PEC.

As bandas espectrais da imagem LANDSAT foram georreferenciadas com base no mosaico e o processo seguiu os mesmos padróes para o RMS. Em seguida, foi elaborada uma composição colorida RGB utilizando as bandas 3, 4 e 5 para orientação do processo de classificaçáo visual que seria realizado posteriormente.

O georreferenciamento foi realizado com base no DATUM SAD 69 e sistema de projeção UTM.

Com as duas imagens devidamente georreferenciadas (mosaico 1964 e LANDSAT 2007), foi delimitada uma área de estudo que englobasse inteiramente o mosaico de ambientes do Estreito (Fig. 4). Com a utilização do módulo WINDOW, as duas imagens foram recortadas nas mesmas proporçóes para que ficassem exatamente com mesmo número de linhas e colunas e a mesma resolução espacial.

Figura 4. Mosaico georreferenciado e delimitação da área de estudo.

\section{Etapa 3 - Digitalizaçáo}

As fotografias aéreas tradicionais, como as utilizadas nesse trabalho, não são adequadas para fins de mapeamento de uso do solo através de classificação automática em SIG em função de uma série de fatores, entre os quais podemos citar a impossibilidade de separar a informação espectral nas diversas faixas do espectro eletromagnético. Já para as imagens dos satélites modernos a informação espectral vem separada, permitindo a classificação automática no SIG com bastante acuracidade.

Assim, optou-se por realizar uma classificação visual através do reconhecimento e digitalização dos polígonos de cada classe temática em ambas as imagens (mosaico 1964 e LANDSAT 2007).

A digitalização foi realizada com o software Cartalinx, desenvolvido pela Clark University, que se aplica à construção

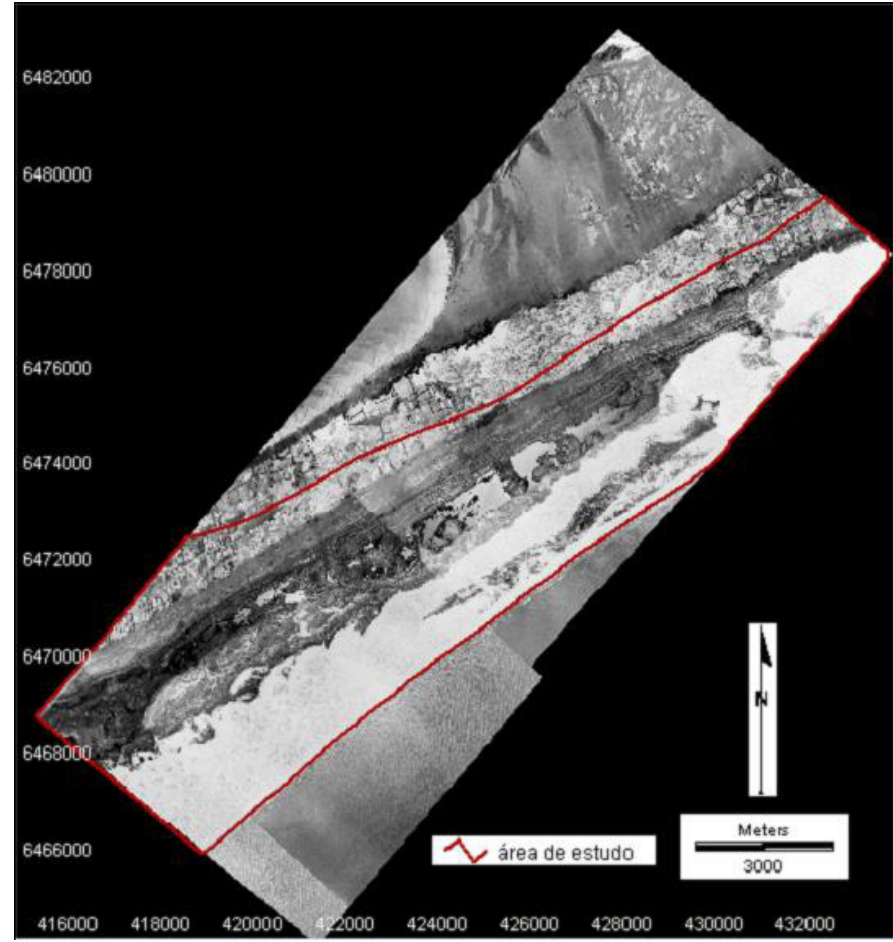

Figura 4. Mosaico georreferenciado e delimitação da área de estudo.

Figure 4. Georeferenced mosaic and delimitation of the study area.

de base de dados relacionais na forma de pontos, vetores e polígonos e trabalha com formatos de arquivos do IDRISI e de outros softwares. Estes dados são tipicamente exportados para um SIG em coberturas (coverages) ou em uma série de mapas de contornos (map layers).

A digitalização foi realizada tomando com base cada uma das imagens georreferenciadas. Inicialmente foram estabelecidos alguns parâmetros antes do início do trabalho, tais como a tolerância e o modo de digitalizaçáo (pontual ou contínua). A tolerância controla a acuracidade e a precisão dos dados de entrada, assim como, a precisão espacial requerida para a seleçấo de feiçóes no processo de edição vetorial.

$\mathrm{O}$ uso do mouse permite traçar ou pontilhar características visíveis nas imagens e dispô-las em uma layer. O programa apresenta uma série de ferramentas que facilitam o processo de digitalização.

Depois de saídas de campo na área de estudo e com auxílio das imagens de satélite, foram definidas as classes de uso atual do solo que seriam mapeadas nas duas situaçóes (1964 e 2007). Cada classe foi digitalizada formando polígonos numerados.

Planícies arenosas, mantos de aspersão eólica e dunas transgressivas foram classificadas como "dunas", devido a grande interação e interdependências dessas feiçóes morfológicas. A classe manejo de pinus representa áreas de corte e repovoamento associadas aos plantios (tabela 1).

\section{Etapa 4 - Análise em SIG}

Os arquivos vetoriais gerados no Cartalinx foram exportados no formato IDRISI 32 vector file (vct) para o ambiente IDRISI Andes e transformados para o formato 
Tabela 1. Classes de cobertura e uso atual do solo.

Table 1. Cover and current land use classes.

\begin{tabular}{ll}
\hline Cod. & Classes \\
\hline 1 & Dunas \\
\hline 2 & Banhados/áreas alagáveis \\
\hline 3 & Lagoas \\
\hline 4 & Matas \\
\hline 5 & Brejos úmidos \\
\hline 6 & Campos / áreas de cultivo \\
\hline 7 & Pinus \\
\hline 9 & Manejo de Pinus \\
\hline 10 & Eucalipto \\
\hline 11 & Estreito: canal/barra \\
\hline
\end{tabular}

raster (matriz digital de linha e colunas) para serem utilizados na análise digital.

Dessa forma, foi possível analisar a variação espaçotemporal entre as diferentes classes de uso mapeadas para as duas situaçóes analisadas (Mapa 1 - 1964 e Mapa 2 2007).

O módulo Crosstab do SIG produz uma nova imagem baseada em todas as combinaçóes de valores das duas imagens. Nessa nova imagem cada sobreposição de classes é reclassificada como uma nova categoria, quantificando a alteração de cada classe em relação às demais. As alterações foram quantificadas em hectares e os dados calculados digitalmente pelo SIG e representados em tabelas.

\section{RESULTADOS E DISCUSSÃO}

Partindo da classificaçáo da cobertura do solo, foram gerados três mapas temáticos, um para cada cenário e outro de sobreposição desses dois cenários que permitiram a quantificação e caracterização dos processos de alteração.

A implantação de florestas de pinus no RS iniciaram nas décadas de 60 e 70 com incentivos fiscais do Governo (Neves et al., 2001). Portanto, no Mapa 1 (Fig. 5), elaborado com base no mosaico de fotografias aéreas de 1964, ainda não existem plantações de pinus.

Os plantios de eucalipo cobrem uma área de 0,7 hectares, que equivalem a 0,009\% da área de estudo, mesmo imperceptível no Mapa 1, essa classe não foi excluída para não interferir na análise estatística. A Barra ou Canal do Estreito foi identificada por uma classe específica para permitir a análise de sua dinâmica em relaçáo à alteração dos ambientes adjacentes. No Mapa 1 essa classe ocupa 0,04\% da área de estudo, portanto quase imperceptível.

No mapa 2, classificado a partir da imagem LANDSAT de 2007, observa-se já a grande interferência dos florestamentos de pinus na paisagem, principalmente à nordeste da área de estudo (Fig. 6).

O módulo crosstab do SIG possibilitou uma análise cruzada entre os dois cenários, gerando um novo mapa que representa as modificaçóes ambientais ocorridas na paisagem entre 1964 e 2007. Foram geradas 37 classes de alteração, das quais, as mais significativas foram analisadas individualmente de acordo com processos naturais e antrópicos atuantes procurando identificar as causas e conseqüências desses processos e a existência ou não de associação com o plantio de pinus. (Fig.7)

Os ambientes costeiros estão sujeitos a alteraçóes naturais a médio e curto prazo, principalmente, em função da sazonalidade das condiçóes climáticas, representadas por ventos predominantes, variaçóes no regime das chuvas e intensidade de insolação. Segundo Tagliani (1995), as

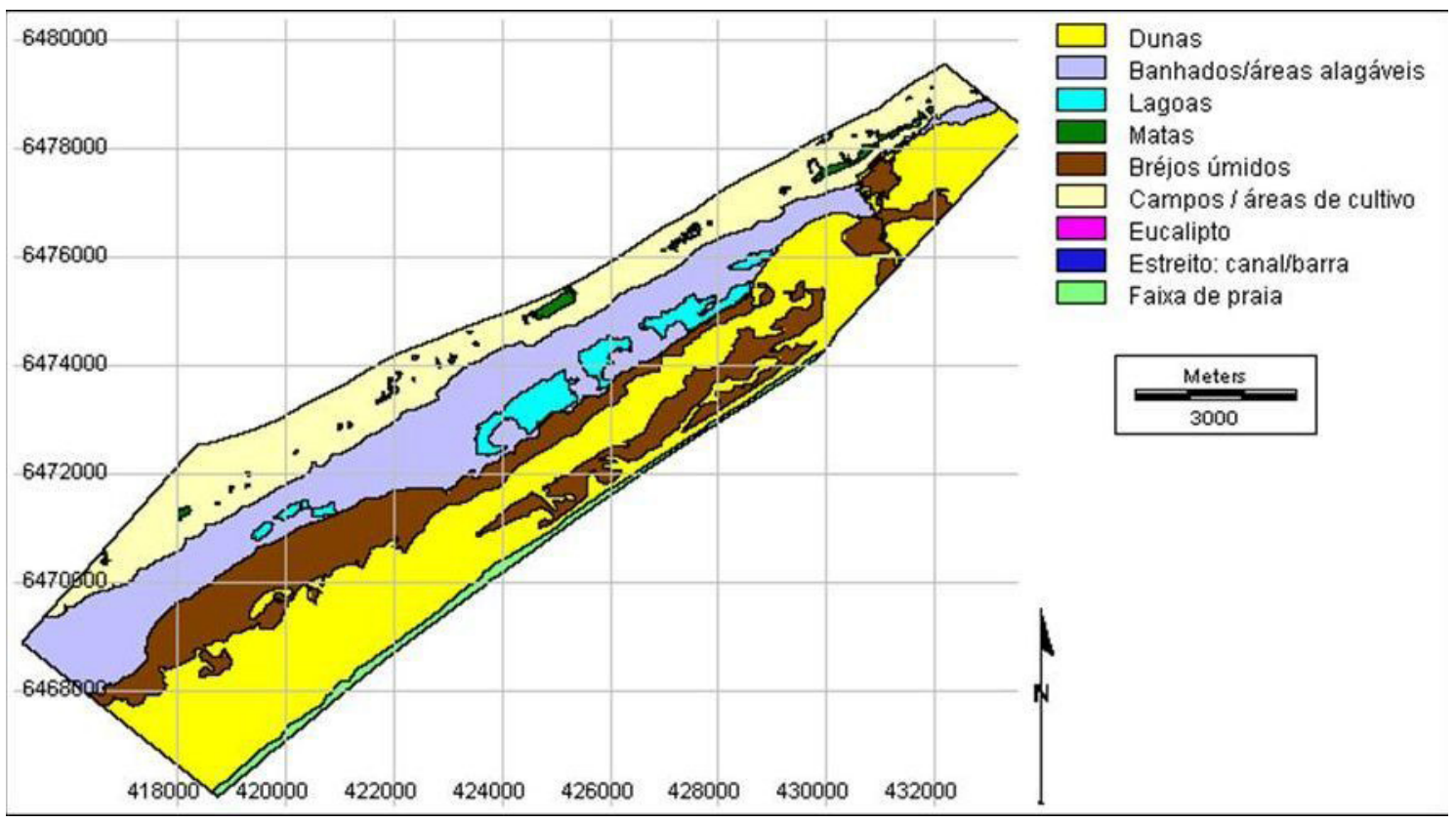

Figura 5. Mapa 1 - Uso e cobertura do solo em 1964.

Figure 5. Map 1 - Use and land cover in 1964. 


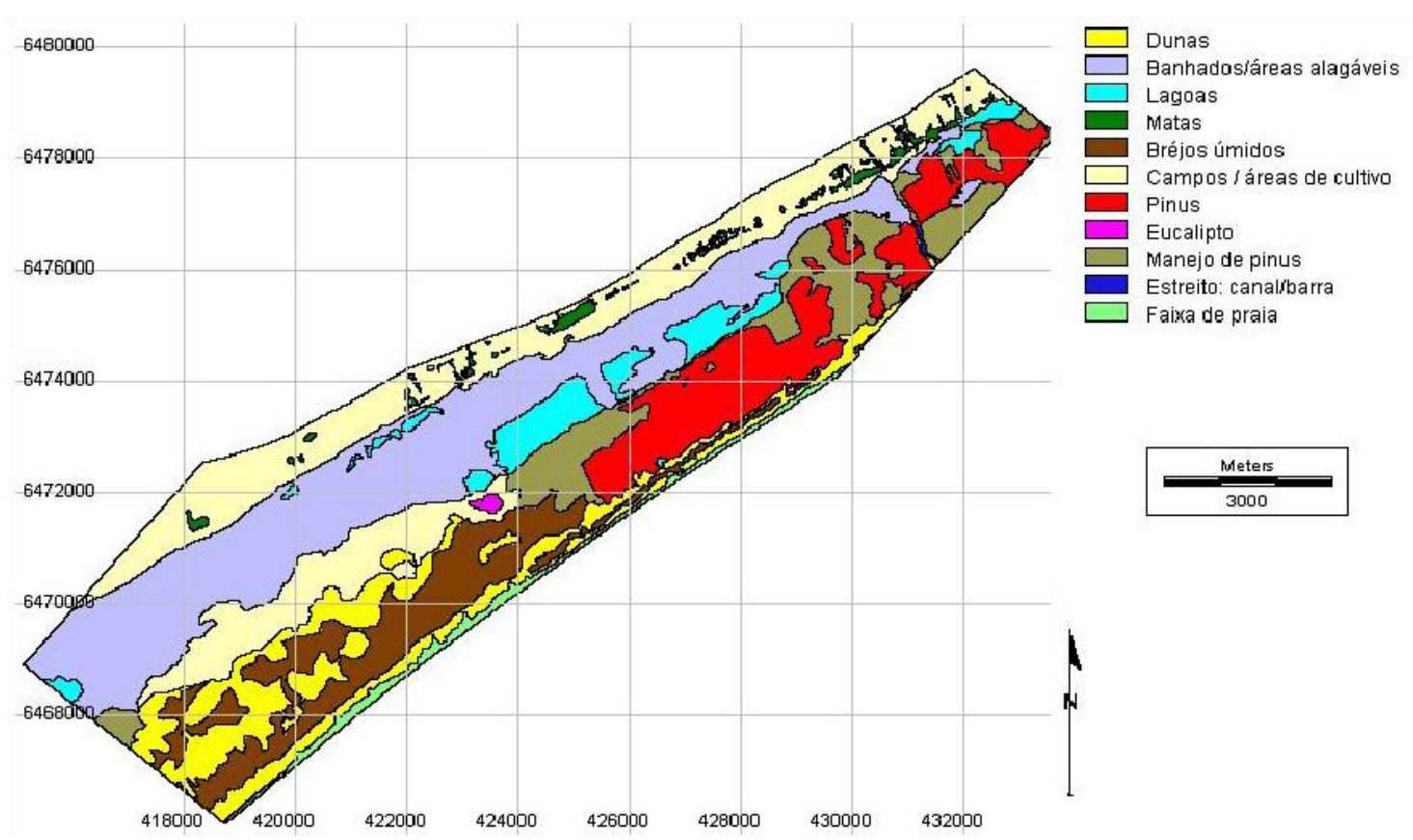

Figura 6. Mapa 2 - Uso e cobertura do solo em 2007.

Figure 6. Map 2- Use and land cover in 2007.

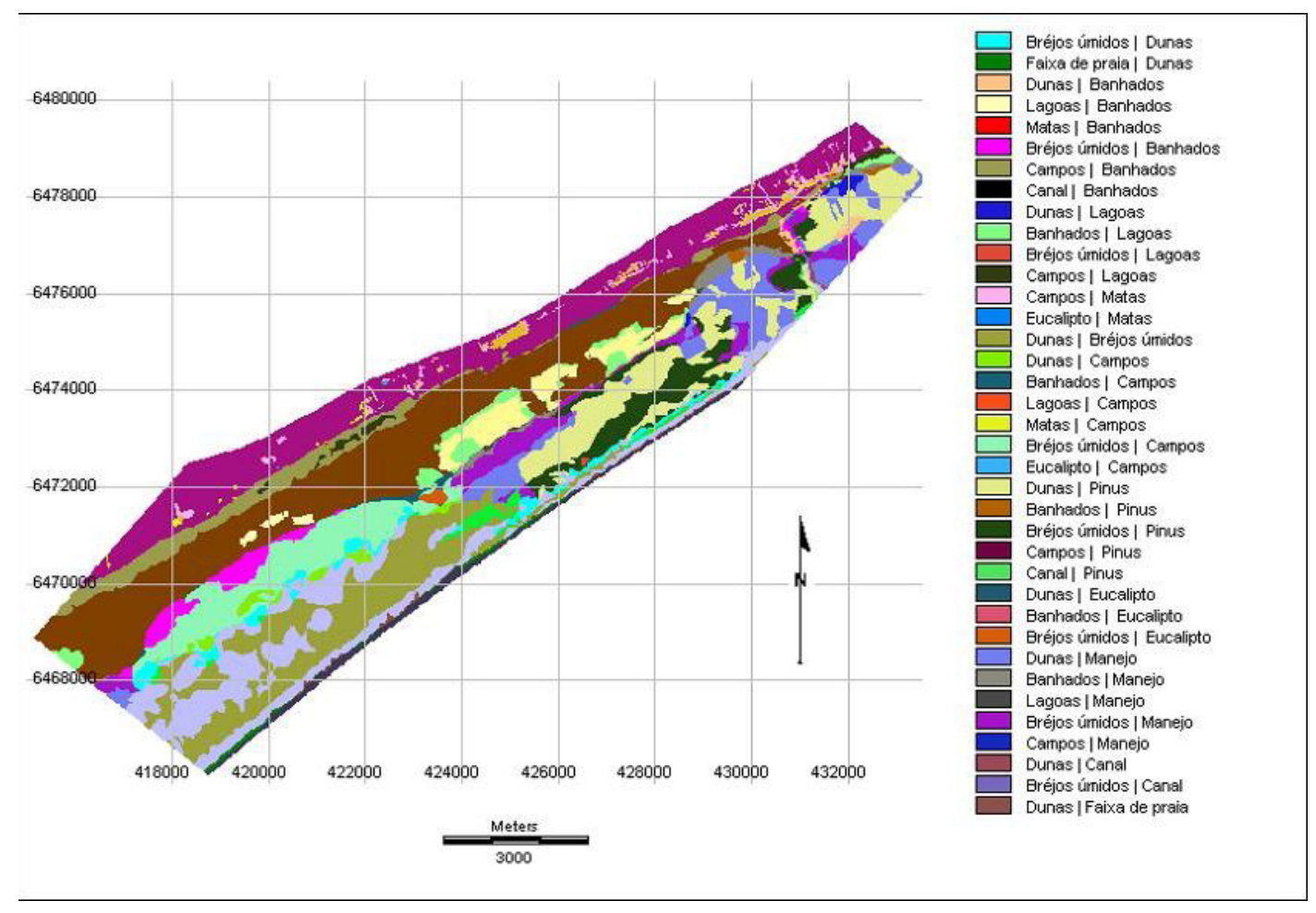

Figura 7. Mapa 3- Análise cruzada 1964 x 2007.

Figure 7. Map 3 - Cross analysis $1964 \times 2007$. 
monoculturas extensivas de arroz e florestamentos de larga escala de pinus são os principais impactos dos sistemas costeiros terrestres, resultando em uma homogeneização do padrão da paisagem e induzindo a uma redução da heterogeneidade espacial.

Partindo do mapeamento, as áreas ocupadas por cada classe e o percentual de ocorrência relativa foram calculadas automaticamente no ambiente SIG e possibilitaram a quantificação da ocupação e o percentual de perda ou ganho ao longo do período estudado (Tabela 2).

Tabela 2. Área ocupada em hectares por cada classe e porcentagem de perda ou ganho.

Table 2. Occupied area by each class in hectares and percentage of loss or gain.

\begin{tabular}{lrrr}
\hline Classes & $\mathbf{1 9 6 4}$ & $\mathbf{2 0 0 7}$ & $\mathbf{\%}$ \\
\hline Dunas & 2529.5 & 884.9 & $-64 \%$ \\
\hline Banhados/áreas alagáveis & 1757.5 & 1984.0 & $+11 \%$ \\
\hline Lagoas & 242.5 & 399.9 & $+39 \%$ \\
\hline Matas & 67.5 & 112.2 & $+40 \%$ \\
\hline Brejos úmidos & 1328.4 & 809.3 & $-60 \%$ \\
\hline Campos / áreas de cultivo & 1611.8 & 1764.6 & $+8,6 \%$ \\
\hline Pinus & 0 & 880.3 & $+100 \%$ \\
\hline Manejo de Pinus & 0 & 700.8 & $+100 \%$ \\
\hline Eucalipto & 0.7 & 12.5 & $+94 \%$ \\
\hline Estreito: canal/barra & 3.2 & 5.9 & $+45 \%$ \\
\hline
\end{tabular}

As plantaçóes de pinus e as áreas de manejo ocupam uma área total de 1.581 hectares, implantadas principalmente sobre dunas transgressivas a leste do sistema lagunar e a norte do canal do Estreito; e em menor escala, sobre brejos úmidos e banhados próximos às lagoas.

Constatou-se que os ambientes que mais sofreram alteraçóes quantitativas, pela interferência dos plantios de pinus e respectivas áreas de manejo, foram as dunas e os brejos úmidos. Segundo Richardson \& Higgins (1998) as dunas e solos expostos são os ambientes mais susceptíveis à invasão por pinus.

As dunas costeiras desempenham importantes funçóes ambientais na proteção de áreas adjacentes - campos, banhados, marismas, cursos d'água e zonas urbanas contra os efeitos de marés altas, ventos e invasão de areia inconsolidada; funcionam como depósito para substituir a areia erodida por ondas ou levadas por tempestades; garantem a estabilidade em longo prazo da frente da praia e exercem uma barreira contra a penetração de água salgada no nível freático, mediante a pressão de água doce que armazenam (Clark, 1977).

$\mathrm{Na}$ regiāo do Estreito, devido à orientação da linha de costa em relaçẫo ao vento $\mathrm{NE}$, ocorrem dunas reduzidas com altura de 0,5 a 1,0 metro, além de planícies arenosas e bacias de deflaçáo (Calliari et al., 2005).

A área original de dunas em 1964 diminuiu 64 \% em relação a 2007, e essa alteração foi causada principalmente pelo estabelecimento de florestas de pinus e áreas de manejo sobre sistemas de dunas fixas, transgressivas ou planícies arenosas (Fig. 8).

A área de dunas ocupada pelos florestamentos de pinus e outras classes de uso do solo está apresentada na Tabela 3.

Seeliger et al. (2000) analisando as mudanças de longo período nas dunas frontais do sudoeste Atlântico, ressalta que

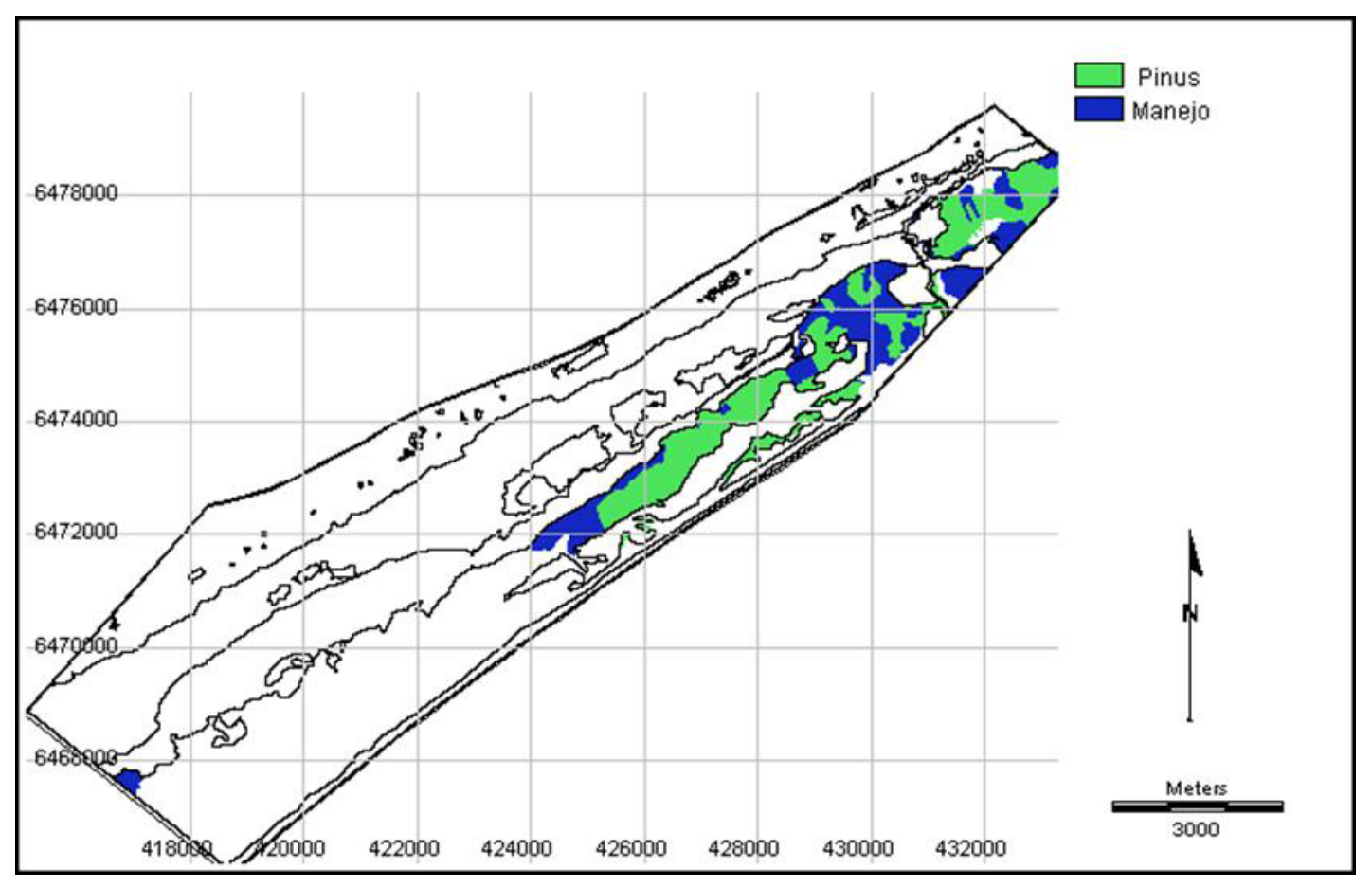

Figura 8. Área original de dunas ocupadas por pinus e áreas de manejo.

Figure 8. Dunes original area occupied by pine and management areas. 
Tabela 3. Ocupação de áreas originais de dunas por outras classes de uso no período analisado.

Table 3. Dune original areas occupation by other classes of use in analised period.

\begin{tabular}{ll}
\hline Classes de uso & Área ocupada (ha) \\
\hline Pinus/ Manejo & 946.6 \\
\hline Brejos úmidos & 740.8 \\
\hline Campos & 56.7 \\
\hline Banhados & 25.0 \\
\hline Lagoas & 19.5 \\
\hline Faixa de Praia & 19.1 \\
\hline Canal & 4.4 \\
\hline Eucalipto & 0.1 \\
\hline
\end{tabular}

entre 1996 e 1998, mantos de areia inconsolidada cobriram os habitats de dunas e formaram dunas trangressivas que se deslocaram sobre os ambientes adjacentes a uma taxa de 31 $\mathrm{m} / \mathrm{ano}$, formando cordóes de retenção em contato com o limite das plantaçôes de pinus.

$\mathrm{Na}$ área de estudo, cordóes de dunas transgressivas próximos aos plantios de pinus, encontram nessas florestas uma barreira à sua migração natural formando dunas de contenção com mais de três metros de altura. A contenção dessas dunas e o comprometimento da sua dinâmica eólica podem causar a desestabilização desse sistema e desencadear processos erosivos, aumentando ou diminuindo o transporte eólico em áreas adjacentes.

De acordo com a fotointerpretação, é possível observar que em 1964, o sistema de dunas transgressivas na região do Estreito, apresentava intensa migração no sentido $\mathrm{NE}$ - SW, em direção a banhados, áreas alagáveis e lagoas. A contenção desse avanço pela plantação de pinus contribuiu para a preservação das funçóes ecológicas desses ambientes.

Os brejos úmidos são ambientes característicos do pósdunas, geralmente localizam-se na interface entre o sistema de dunas costeiras, banhados e campos. Apresentam espécies vegetais características desses três ambientes e estão sujeitos a alagamentos em períodos de chuvas intensas e soterramento por dunas transgressivas e mantos de aspersáo eólica.

A área originalmente ocupada pelos brejos úmidos em 1964 diminuiu $60 \%$ em relação a 2007. Como esse ambiente geralmente apresenta-se associado ao sistema de dunas, essa alteração foi causada principalmente pelo estabelecimento dos florestamentos de pinus e áreas de manejo sobre esses ambientes. As áreas de pinus e manejo ocupam atualmente 530,3 hectares em áreas originalmente cobertas pelos brejos.

No Mapa 2- 1964 (Fig. 4), identifica-se uma extensa área de brejos úmidos observada paralelamente ao sistema de lagoas, entre o cordão de dunas e a faixa de praia. Esse sistema, apresentava uma ligação com a lagoa do Estreito, que em períodos chuvosos auxiliavam no escoamento das águas das lagoas em direção ao oceano pelos sangradouros.

Toda essa área de brejos e ainda outros associados ao canal e a barra do Estreito, deram lugar a florestas e áreas de corte e repovoamento de pinus (Manejo de pinus), o que provavelmente resultou na alteração do padrão de drenagem do sistema de lagoas (Fig. 9).

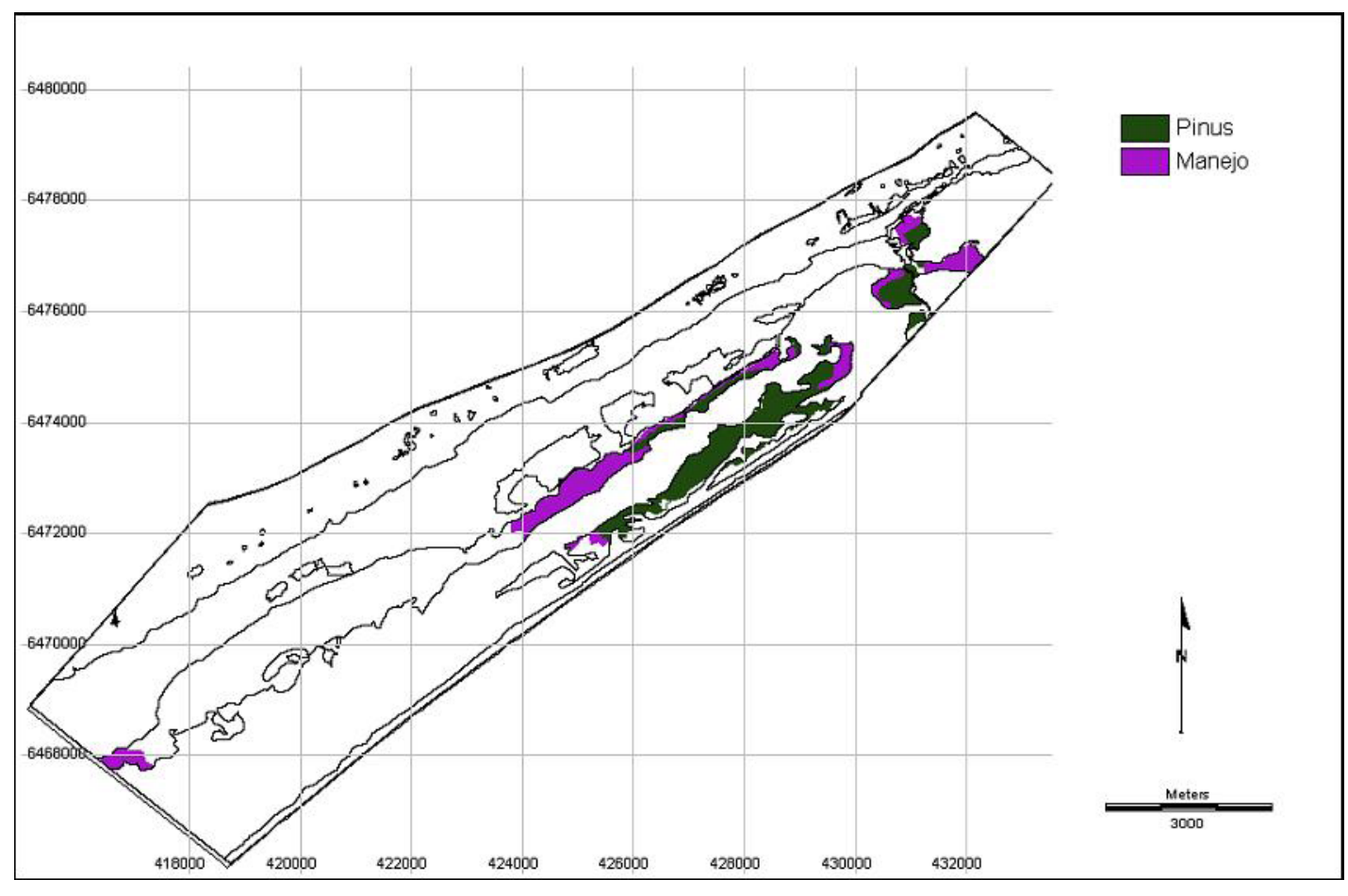

Figura 9. Área original de brejos ocupada por pinus e áreas de manejo.

Figure 9. Humid slacks original area occupied by pine and management areas. 
As alteraçóes relacionadas às outras classes, provavelmente dizem respeito a processos naturais como alagamentos, soterramento e sucessão ecológica, com exceção de 11,7 hectares que foram plantados com eucalipto (Tabela 4).

Tabela 4. Ocupação de áreas originais de brejos úmidos por outras classes de uso no período analisado.

Table 4. Humid slacks original areas occupation by other classes of use in analised period.

\begin{tabular}{ll}
\hline Classes de uso & Área ocupada (ha) \\
\hline Pinus/ Manejo & 530.3 \\
\hline Campos & 449.0 \\
\hline Dunas & 135.5 \\
\hline Banhados & 128.0 \\
\hline Eucalipto & 11.7 \\
\hline Lagoas & 3.6 \\
\hline
\end{tabular}

\subsection{Alteraçóes na dinâmica dos ambientes}

Foram observadas alteraçóes consideráveis em outros ambientes, provavelmente resultantes da interferência dos maciços florestais em processos naturais da dinâmica costeira, tais como: transporte eólico, fluxo hídrico e sucessão ecológica.

É possível que a barreira formada pelas florestas de pinus tenha diminuído o transporte eólico lateral, contribuindo para o aumento dos brejos úmidos na porção sul da área de estudo, anteriormente ocupada por dunas transgressivas e sujeita a intenso transporte eólico (Fig. 10).
Essas alteraçóes também podem ser responsáveis pelo povoamento de gramíneas em áreas anteriormente mais úmidas, resultando na migração dos brejos em direção à praia e permitindo a expansão dos campos nas áreas mais altas. A sudoeste do sistema de lagoas uma faixa com cerca de $6,5 \mathrm{~km}$ de extensão e área de 449 hectares, originalmente cobertas pelos brejos, passaram a ser ocupadas por campos.

O nível das lagoas e banhados e a migração de dunas são processos sujeitos a essa dinâmica sazonal e apresentam mudanças significativas em um curto espaço de tempo.

O sistema de lagoas do Estreito apresenta uma área de 400 hectares equivalente a aproximadamente $5 \%$ da área analisada. Constatou-se que em relação a 1964, ouve um aumento de $39 \%$ na área ocupada pelas lagoas.

A precipitação média acumulada durante o mês de maio de 2007, de acordo com dados da Estação Meteorológica do $8^{\circ}$. Distrito de Meteorologia do Instituto Nacional de Meteorologia (INMET) foi muito próxima do valor da normal climatológica de Rio Grande $(100 \mathrm{~mm})$, calculada com base nas médias mensais de dez anos (1991-2000),e os meses anteriores também não apresentaram nenhuma anomalia quanto ao volume de precipitação (Fig.11).

Portanto, o aumento da área das lagoas pode ser resultado da obstrução das drenagens naturais pelas plantaçóes de pinus próximas as dunas, ocasionando a diminuição do número de sangradouros e resultando em alteraçóes no padrão de drenagem das lagoas e banhados. Essas alteraçóes podem ser responsáveis pelo redirecionamento do fluxo de drenagem para outras áreas e no aumento do nível de banhados e lagoas em períodos de alto índice pluviométrico.

Porém, como não foi possível estabelecer a data precisa das fotografias aéreas de 1964, e dessa forma, identificar o regime de chuvas na época, o aumento da área das lagoas e banhados náo pode ser associado inequivocamente à interferência causada pelos plantios de pinus.

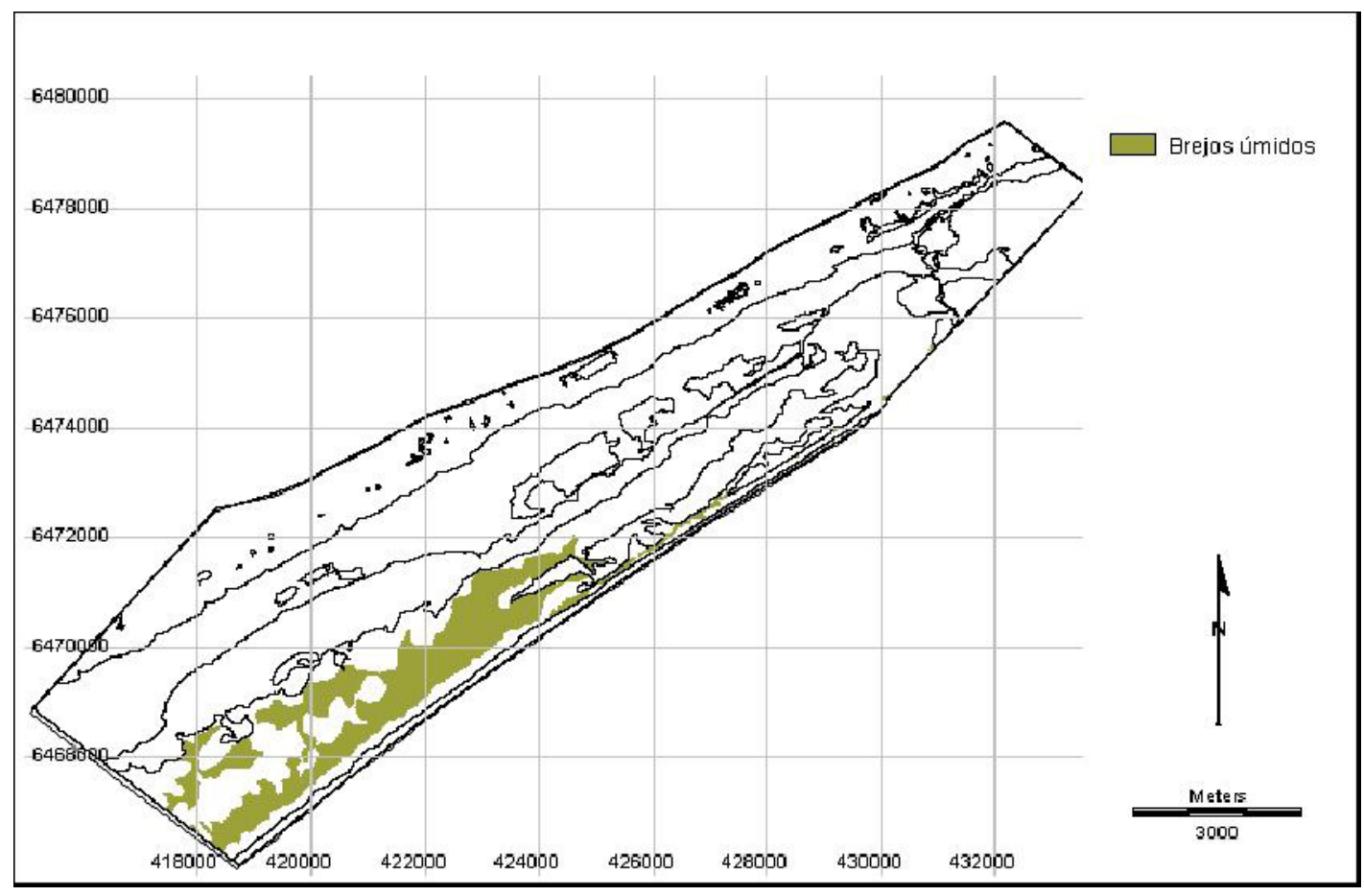

Figura 10. Área original de dunas ocupada por brejos úmidos.

Figure 10. Dunes original area occupied by wetlands. 


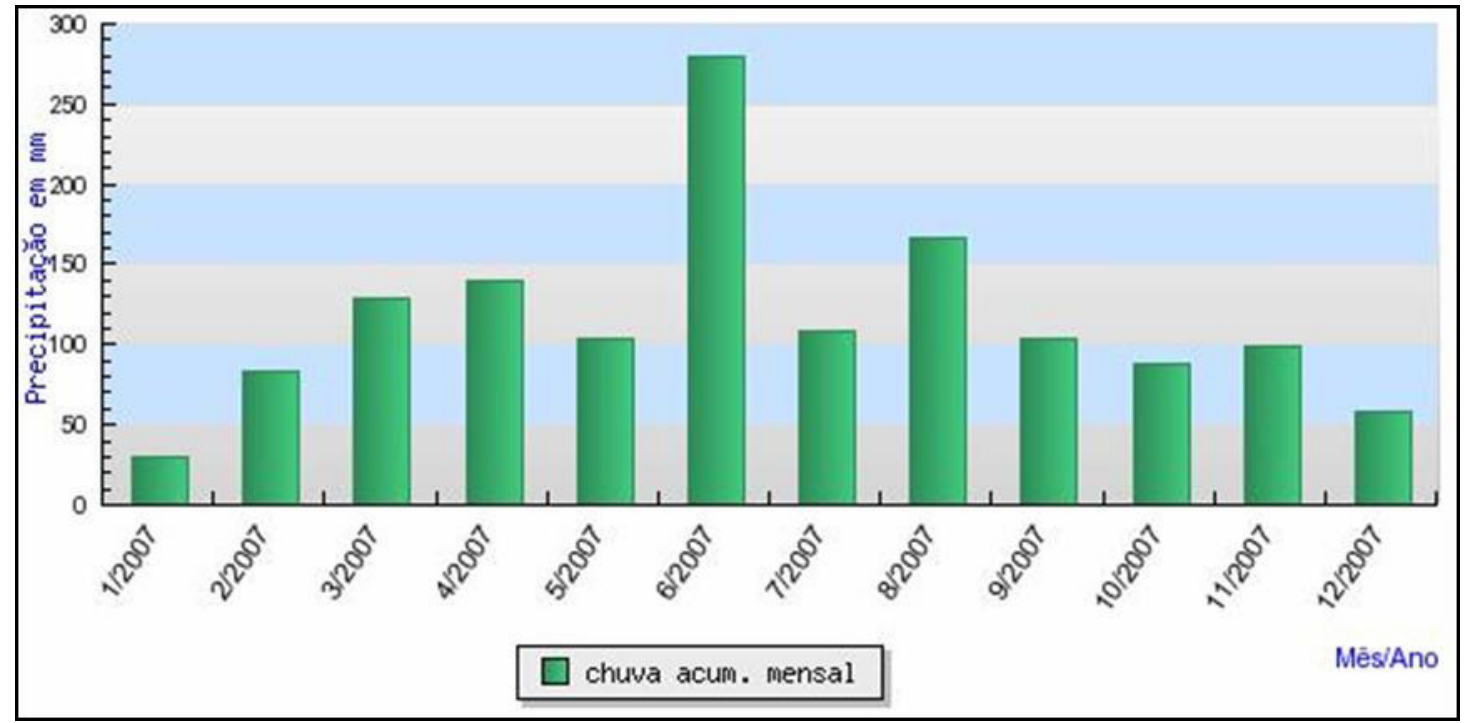

Figura 11. Precipitação acumulada mensal para Rio Grande - 2007.

Figure 11. Monthly rainfall for Rio Grande - 2007.

De acordo com a análise, em 2007 a área das lagoas teve um aumento de 144.4 hectares, sobre áreas que em 1964, eram coberta por banhados.

Os banhados são áreas alagadas permanente ou temporariamente, apresentam alta produtividade orgânica e biodiversidade e são importantes na regulação do fluxo hídrico dos sistemas os quais fazem parte.

Segundo Schwarzbold \& Schäfer (1984), na região sul do RS, os banhados estáo associados principalmente às lagoas costeiras, apresentando uma grande variedade de comunidades vegetais macrofíticas que variam segundo o regime hidrológico, morfometria e outras características físicas de cada sistema.

$\mathrm{Na}$ região do estreito as maiores extensões de banhados ocorrem associadas ao sistema de lagoas. A área de banhados aumentou $11 \%$ em relação a 1964 , principalmente sobre áreas originalmente cobertas por campos e brejos úmidos.

Observou-se que o limite entre a área de banhados e campos avançou cerca de 500 metros na sua porção sudoeste, ocupando 295 hectares; na direçấo oposta, observa-se o avanço dos banhados sobre áreas originalmente cobertas por brejos úmidos em 128 hectares.

As mesmas hipóteses apresentadas para o aumento do nível das lagoas podem estar relacionadas aos banhados, já que estes, também apresentaram um significativo aumento em sua área e estấo associados ao sistema de lagoas.

Os campos litorâneos compreendem formações herbáceas de baixo porte, com fisionomia e características taxonômicas semelhantes, considerando a uniformidade de formas biológicas e o habitat ocupado pelas mesmas. Constituem as comunidades vegetais predominantes em termos regionais, a composiçáo e estrutura estão associadas a fatores edáficos bem definidos (Tagliani, 2002).

A área coberta por campos aumentou 8,6\% em relação à área observada em 1964. Esse aumento é representado por uma área anteriormente coberta por brejos, localizada a sudoeste do sistema de lagoas em uma faixa com cerca de $6,5 \mathrm{~km}$ de extensão e área de 449 hectares (Fig.12 e Tabela 5).

A sucessão ecológica de ambientes pode ser atribuída a processos naturais, porém, como essa alteração foi observada em uma área diretamente associada ao sistema de lagoas e anteriormente sujeita a processos eólicos intensos que foram alterados pela plantação de pinus, supõe-se que a dinâmica e a associação entre os ambientes possa ter sofrido influência antrópica, representada pelos florestamentos.

$\mathrm{Na}$ área de estudo as matas de restinga ocupavam anteriormente 67,5 hectares, atualmente essa área aumentou $39,8 \%$, passando para 112,2 hectares. $\mathrm{O}$ aumento dessa área ocorreu no entorno dos remanescentes naturais.

Esse considerável aumento observado em 43 anos pode estar associado ao aumento dos instrumentos de proteção legais a partir de 1964, com instituição do Código Florestal Brasileiro (Lei n4.771/65), e em 1998 com a Lei de Crimes Ambientais (Lei ${ }^{\circ} 9.605 / 98$ ).

Além desses aspectos, a implantação das florestas de pinus como fonte de madeira, pode ter contribuído para diminuir a pressão sobre as matas nativas. Devido ao alto potencial de dispersão, o pinus necessita manejo permanente, tanto nos grandes maciços florestais, como em pequenas propriedades rurais, resultando em uma abundante fonte de madeira.

\section{CONCLUSÃO}

Constatou-se que na regiáo do Estreito, a maioria dos plantios em grande escala foi estabelecida sobre planícies arenosas formadas por Neossolos próximas a praia e podem ser responsáveis por alterações na dinâmica dos ambientes adjacentes, na distribuição dos sangradouros, na contenção de dunas móveis, na fragmentação de habitat e na perda de biodiversidade.

O estabelecimento desses plantios sobre o sistema de dunas póe em risco varias espécies vegetais e animais que dependem diretamente da integridade ambiental dos seus habitats naturais, destaque para o tuco-tuco (Ctenomys flamarioni), 


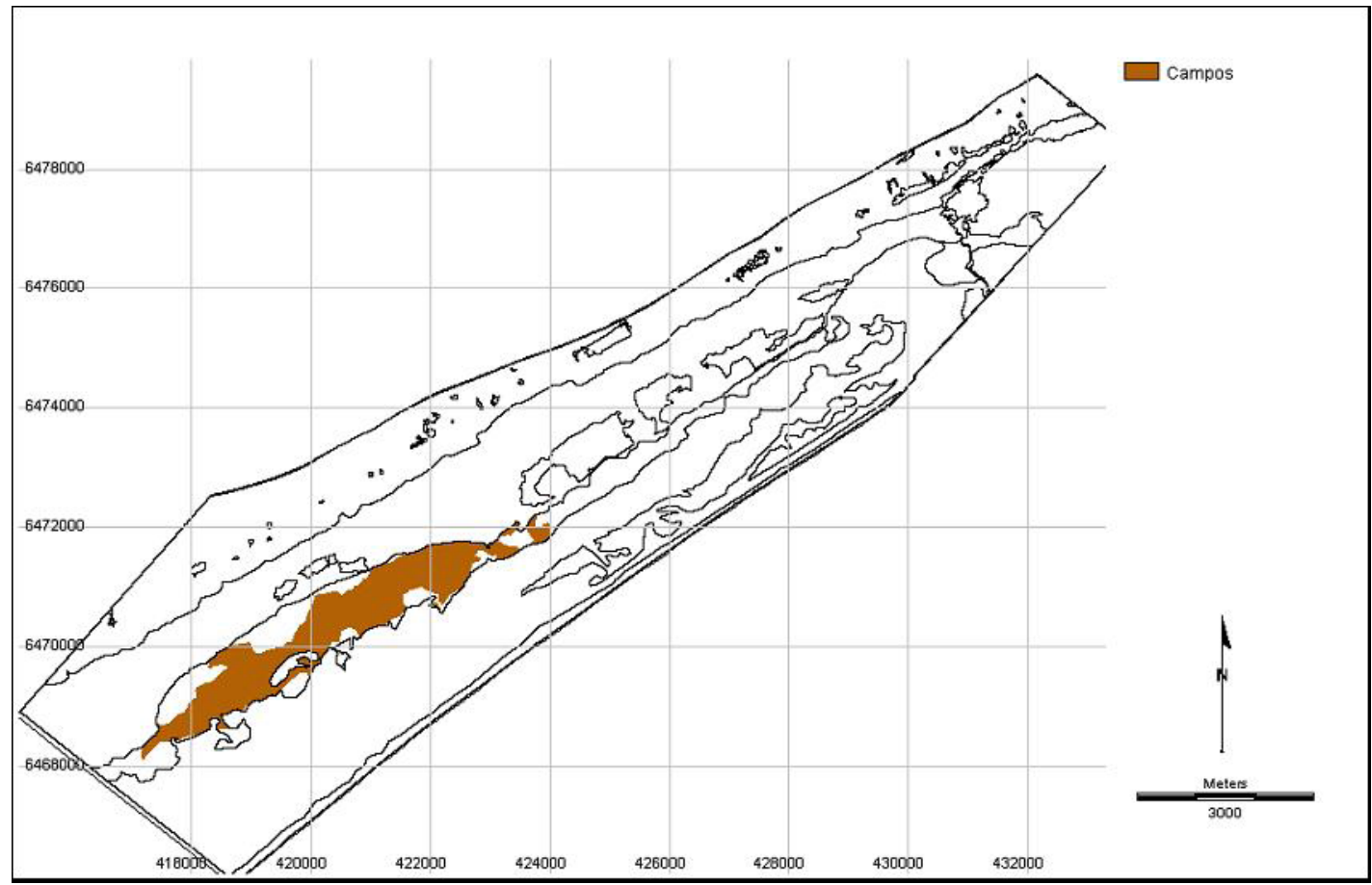

Figura 12. Área original de brejos ocupada por campos.

Figure 12. Humid slacks original area occupied by fields.

Tabela 5. Área das classes convertidas em campos em hectares. Table 5. Area of each class converted to fields in hectares.

\begin{tabular}{ll}
\hline Classe & Área $($ ha) \\
\hline Brejos úmidos & 449.0 \\
\hline Dunas & 56.7 \\
\hline Matas & 27.8 \\
\hline Banhados & 25.9 \\
\hline
\end{tabular}

mamífero roedor endêmico classificado como vulnerável à extinção devido a degradação das dunas costeiras.

Quanto às alteraçôes na paisagem na regiấo do Estreito, constatou-se que as plantaçôes próximas à praia podem interferir na dinâmica de alguns ambientes e na descaracterização da área onde forem implantados.

Dunas trangressivas e brejos úmidos foram totalmente suprimidos por essas plantaçóes em uma área de aproximadamente 1.500 hectares, consequentemente resultando na diminuição da fauna e erradicação da flora desses ambientes.

Supóe-se que esses plantios próximos ao sistema de dunas tenham interferido no processo de migração de dunas transgressivas em direção as lagoas e banhados, e também, barrado o transporte eólico lateral que alimentava as planícies arenosas localizadas mais ao sul, onde atualmente ocorrem brejos úmidos.

Outra hipótese é que a barreira estabelecida pelos plantios tenha resultado no represamento das águas do sistema de lagoas do Estreito, diminuindo o número de sangradouros.
Mudanças na dinâmica desses ambientes evidenciam a conectividade entre os sistemas, principalmente em relação ao fluxo hídrico e sedimentar. A alteração do transporte eólico e do escoamento dos banhados e lagoas provavelmente está relacionada com o efeito de barreira formada pelas plantaçóes de pinus.

Questóes referentes a impactos gerados por esses florestamentos em relação aos diferentes tipos de solos, recursos hídricos, ambientes naturais e biodiversidade, devem ser analisados em cada situaçáo, visto que, os ambientes diferem em aspectos ecológicos importantes como: vulnerabilidade, resiliência, regeneração, fluxo gênico e outros.

Os resultados desse estudo contribuem ditetamente para a gestão dos recursos naturais nas zonas costeiras. A identificaçáo das alteraçôes na paisagem causadas por intervenções antrópicas e a análise da dinâmica dos ambientes alterados, pode servir de subsídio para o pranejamento das atividades e o manejo sustentável da áreas naturais.

Dessa forma, contribuindo para uma gestão mais eficaz dos ambientes costeiros, e assim promovendo o uso sustentável dessas áreas.

\section{BIBLIOGRAFIA}

Bechara, F.C. (2003) - Restauração Ecológica de Restingas Contaminadas por Pinus no Parque Florestal do Rio Vermelho, Florianópolis, SC. 125p., Dissertação, Programa de Pós-Graduação em Biologia Vegetal, Universidade Federal de Santa Catarina, Florianópolis, SC, Brasil. Disponível em http://www.ipef.br/servicos/teses/arquivos/ bechara,fc-m.pdf 
Calliari, L.J.; Pereira, P S.; de Oliveira, A.O.; Figueiredo, S.A. (2005) - Variabilidade das dunas frontais no Litoral Norte e Médio do Rio Grande do Sul, Brasil. Gravel (ISSN: 1678-5975), 3:15-30. Porto Alegre, RS, Brasil. http://www.ufrgs.br/ceco/gravel/3/CD/docs/Gravel_3_03.pdf

Clark, J.R. (1977) - Coastal ecosystem management: a technical manual for the conservation of coastal zone resources. 928p., John Wiley \& Sons, New York, NY, U.S.A. ISBN: 9780471158547.

CONSEMA (2000) - Resolução CONSEMA n. ${ }^{\circ}$ 11, de 17 de novembro de 2000 - Estabelece diretrizes para o Plano Ambiental Municipal, nos termos da resolução/CONSEMA n. ${ }^{\circ} 04 / 2000$. http://www.mp.rs. gov.br/ambiente/legislacao/id401.htm

D.O.U. (1984) - Decreto 89.817 de 20 de junho de 1984 Estabelece as Instruções Reguladoras das Normas Técnicas da Cartografia nacional. Diário Oficial da República Federativa do Brasil, Brasília, no . 120, 22 de junho de 1984, Brasília, DF, Brasil. Disponível em http://www. planalto.gov.br/ccivil_03/decreto/1980-1989/D89817.htm

Eastman, J.R. (1997) - Idrisi for Windows: User's Guide : Version 2.0. 192p., Clark University, Department of geography, Worcester, MA, U.S.A.

Figueiredo, S.A.; Calliari, L.J. (2005) - Sangradouros: Distribuição Espacial, Variação Sazonal, Padrôes Morfológicos e Implicaçóes no Gerenciamento Costeiro. Gravel (ISSN 1678-5975), 3:47-57, Porto Alegre, RS, Brasil.

Gianuca, K.S. (2009) - Aspectos socioeconomicos e ambientas da exploração de pinus sp. No municipio de São José do Norte $e$ análise das alteraçóes na paisagem em áreas adjacentes aos plantios na regiáo do Estreito entre os anos de 1964 e 2007. Dissertação de Mestrado, PPGEO - Programa de Pós Graduação em Geografia, FURG, Rio Grande, RS, Brasil. Não publicado.

Grando, Marinês Zandavali; Fochezatto, Adelar (coord.) (2008) - Impactos dos investimentos na cadeia florestal sobre a economia do Rio Grande do Sul. 93p., FEE - Fundação de Economia e Estatística. Secretaria do Planejamento e Gestão. Porto Alegre, RS, Brasil. ISBN: 9788571730649. Disponível em http://www.fee.tche.br/sitefee/pt/content/ publicacoes/pg_impactos_dos_investimentos.php

IBGE (2007) - Produção da Extração Vegetal e Silvicultura. v. 22, p.1-47, IBGE - Instituto Brasileiro de Geografia e Estatística, Rio de Janeiro, RJ, Brasil. ISSN: 0103-8435. Disponível em http://www.ibge.gov.br/home/estatistica/ economia/pevs/2007/pevs2007.pdf
Machado,R.E. ; Vettorazzi, C.A.; Xavier, A.C. (2003) Simulação de cenários alternativos de uso da terra em uma microbacia utilizando técnicas de modelagem e geoprocessamento. Revista Brasileira Ciência do Solo (ISSN: 0100-0683), 27(4):727-733, Viçosa, MG, Brasil. http://www.scielo.br/pdf/rbcs/v27n4/a17v27n4.pdf

Neves, G.A.; Martins, C.A.; Miyasava, J.; Moura, A. F. (2001) - Análise econômico-financeira da exploração de pinus resinifero em pequenos módulos rurais. Monografia de Especialização em Agrobusiness, 48p., USP, São Paulo, SP, Brasil. Não Publicado.

Richardson, D.M.; Higgins, S.I. (1998) - Pines as invaders in the southern hemisphere. In: D. M. Richardson (ed.), Ecology and Biogeography of pinus, pp. 450-473, Cambridge University Press, Cambridge, U.K. ISBN: 9780521789103.

Schwarzbold, A.; Schäfer, A. (1984) - Gênese e morfologia das lagoas costeiras do Rio Grande do Sul. Amazoniana (ISSN: 0065-6755), 9(1):87-104.

Secretaria Estadual do Meio Ambiente (1994) - Lei Estadual no 10.330 de 27 de dezembro de 1994 - Dispóe sobre a organização do Sistema Estadual de Proteção Ambiental, a elaboração, implementação e controle da política ambiental do Estado e dá outras providências. Disponível em http://www.mp.rs.gov.br/ambiente/legislacao/id5002.htm

Seeliger, U.; Cordazzo, C.V.; Oliveira, C.P.L.; Seeliger, M. (2000) - Long-term changes of a coastal foredunes in the southwest Atlantic. Journal of Coastal Research (ISSN: 0749 - 0208), 16(4): 1068-1072. West Palm Beach, FL, U.S.A.

Tagliani, C.R.A. (2002) - Mineração na porçâo média da Planície Costeira do Rio Grande do Sul: Estratégia para gestão sob um enfoque de Gerenciamento Costeiro Integrado. Tese de Doutorado. Universidade Federal de Rio Grande do Sul. Porto Alegre, RS, Brasil.

Tagliani, P.R. (1995) - Estratégia de Planificação Ambiental para o Sistema Ecológico da Restinga da Lagoa dos PatosPlanície Costeira do Rio Grande do Sul. Tese de Doutorado em Ecologia e Recursos Naturais, Centro de Ciências Biológicas e da Saúde, Universidade Federal de São Carlos, SP., Brasil. Não publicado.

Villwock, J.A. (1984) - Geology of the Coastal Province of Rio Grande do Sul, Southern Brazil: A Synthesis. Pesquisas, 16:5-49, Porto Alegre, RS, Brasil. 